1. MBBS, M.Phil

Assistant Professor Biochemistry

United Medical \& Dental College.

2. MBBS, M.Phil

Assistant Professor Biochemistry

Karachi Institute of Medical

Sciences Karachi.

3. MBBS, M.Phil

Assistant Professor Pharmacology

Aziz Fatimah Medical \& Dental

College.

4. MBBS, M.Phil

Assistant Professor Pathology

Liaquat College of Medicine and Dentistry.

5. MBBS, MPH

Assistant Professor Community

Health Sciences

United Medical \& Dental College.

Correspondence Address:

Dr. Naveed Ahsan

Department of Biochemistry

United Medical \& Dental College.

dr_naveedahsan@yahoo.com

Article received on:

27/03/2019

Accepted for publication:

$21 / 06 / 2020$

\section{Status of serum uric acid in diabetic and non-diabetic subjects.}

\author{
Naveed Ahsan', Fasiha Fatima², Sarwat Jahan ${ }^{3}$, Shahid Zafar ${ }^{4}$, Jai Kershan ${ }^{5}$
}

ABSTRACT... Objectives: The purpose of the research is to assess the status of serum uric acid in non-diabetic and diabetic subjects. Study Design: Cross Sectional Comparative study. Setting: Department of Medicine Jinnah Postgraduate Medical Center, Karachi. Period: Feb 2018 till September 2018. Material \& Methods: A total of 80 subjects of both sexes were taken and divided into two groups. Fasting glucose levels, serum uric acid were performed by enzymatic method. Results: This study showed significantly raised levels of serum uric acid and Fasting blood glucose (FBS) in diabetic type 2 subjects when compared to non-diabetic subjects $(p<0.01)$. Conclusion: The results of the present study suggests that compared to non-diabetic subject's diabetic subjects have significantly higher level of uric acid.

Key words: $\quad$ Diabetes Mellitus, Serum Uric Acid.

Article Citation: Ahsan N, Fatima F, Jahan S, Zafar S, Kershan J. Status of serum uric acid in diabetic and non-diabetic subjects. Professional Med J 2020; 27(11):24582462. https://doi.org/10.29309/TPMJ/2020.27.11.3457

\section{INTRODUCTION}

About 200 million people worldwide are affected from Diabetes mellitus, with a prevalence of $10 \%$ in Pakistan. In diabetes mellitus insulin hormone is absolutely or relatively deficient and the risk to develop stroke, heart attack, kidney failure, blindness, coronary artery disease, neuropathy and gangrene are increases. ${ }^{1}$ About 7 million populations of Pakistani adults suffer from diabetes, and about the same number have impaired glucose tolerance. ${ }^{2}$ Among those countries which have highest diabetic population Pakistan ranks at $6^{\text {th }}$ position. ${ }^{3}$

Uric acid $\left(2,6,8 \text { trioxypurine- } \mathrm{C}_{5} \mathrm{H}_{4} \mathrm{~N}_{4} \mathrm{O}_{3}\right)^{4}$ is an organic compound which is formed as a purine metabolite in a human body. The risk to develop hypertension, cardiovascular disease and chronic kidney disease are more in hyperuricemia. ${ }^{5}$ The hyperuricemia is basically serum uric acid $\geq 7$ $\mathrm{mg} / \mathrm{dl}$ for males and $6 \mathrm{mg} / \mathrm{dl}$ for females. ${ }^{6}$ The mechanism through which hyperuricemia is associated with cardiovascular disease is unclear due to its relation with the established risk factor of diabetes mellitus, hypertension, and obesity etc. Elevated uric acid considered as one of the metabolic abnormalities associated with hyperinsulinemia which can be seen in NIDDM and impaired glucose intolerance. ${ }^{7}$ Some studies shows direct link among raised uric acid levels and diabetes, while other studies have shown no association or an inverse relationship. So, it remains ambiguous whether uric acid may have link with the development of type 2 diabetes or not limited information is available on this subject in Asia, which is why we evaluate the status of uric acid level patients of diabetes mellitus type 2 in a tertiary care hospital.

\section{MATERIAL \& METHODS}

This study was approved by the united medical and dental college research ethics committee. Research was conducted according to the principles expressed in the declaration of Helsinki. Participants involved in this study were volunteers who were explained the minimal risk research procedure. Verbal and written informed consent was taken from all the volunteers involved in this study. 


\section{Study Population}

This is a cross sectional comparative study carried out in tertiary care unit from February 2018 to September 2018. Total 80 subjects of both sexes were included in our study which was divided into two groups. Sample size was calculated by open Epi software.

Group A: Normal healthy subjects taken as controls $(n=40)$

Group B: Non-Insulin Dependent diabetes cases $(n=40)$

Patient with chronic liver disease, Thyroid dysfunction and history of renal disorder. Patients on drugs like oral hypoglycemic, thiazide diuretics, anti-hypertensives, cytotoxic drugs, cyclosporine, anti-tubercular drugs like ethambutol \& pyrazinamide, recent intake of allopurinol \& women's on oral contraceptives are excluded from our study

Blood samples were collected from antecubital vein after 8-10 hours overnight fasting. All the samples were then centrifuged at $80 \times \mathrm{xg}(3000 \mathrm{rpm})$ for 10 minutes and supernatant was separated. Fasting glucose was done by GOD-PAP (Glucose Oxidase-Phenol-Aminophenazone) method (Merck France).Serum uric acid, assayed by uricase method (Merck France).

Data were analyzed by using SPSS (Version 16). Data on continuous variables i.e. biophysical parameters (age, height, weight, BMI, blood pressure) statistically analysis by using chisquare test and biochemical parameter (serum fasting blood glucose, serum uric acid) were calculated as mean \pm standard deviation(SD) by using a student t-test. In all statistical analysis performed, $p$-values $<0.01$ were considered statistically significant.

\section{RESULTS}

Subjects involved in this study were 80 and they were divided in two groups. Group A consist of 40 non-diabetic healthy subjects and group $B$ consist of 40 diabetes type 2 subjects. All the subjects were age matched and therefore no significant difference was seen between the groups.

Table-I consist with biophysical variables and there is no significant differences were found in height, weight, body mass index, systolic and diastolic blood pressure. But the mean serum uric acid and fasting blood sugar were significantly increased in diabetes type 2 subjects.

Figure-1 shows the significantly increased serum uric acid in diabetic type 2 subjects when compared to the non-diabetic subjects (control).

Figure-2 show that serum uric acid was significantly increased in diabetic male and female when compared to the non-diabetic male and females.

\begin{tabular}{|c|c|c|}
\hline Variables & $\begin{array}{c}\text { Non diabetic } n=(40) \\
\text { Mean } \pm S . D\end{array}$ & $\begin{array}{c}\text { Diabetic Type } 2 \mathrm{n}=(40) \\
\text { Mean } \pm \text { S.D }\end{array}$ \\
\hline Age in years & $49.78 \pm 5.76$ & $50.15 \pm 4.54$ \\
\hline Weight(Kg) & $69.7 \pm 8.959$ & $70.2 \pm 9.033$ \\
\hline Height(meter $\left.{ }^{2}\right)$ & $1.682 \pm 0.068$ & $1.701 \pm 0.061$ \\
\hline Diastolic blood pressure $(\mathrm{mm} / \mathrm{Hg})$ & $78.875 \pm 3.098$ & $84.125 \pm 5.761$ \\
\hline Systolic blood pressure(mm/Hg) & $115.675 \pm 4.086$ & $125 \pm 4.825$ \\
\hline Serum uric acid (mg/dl) & $4.485 \pm 0.684$ & $8.635 \pm 0.903^{*}$ \\
\hline Fasting blood sugar (mg/dl) & $92.72 \pm 7.958$ & $152.95 \pm 17.991^{*}$ \\
\hline
\end{tabular}




\section{Comparison of Serum Uric Acid between Diabetic and \\ Non Diabetic subjects.}

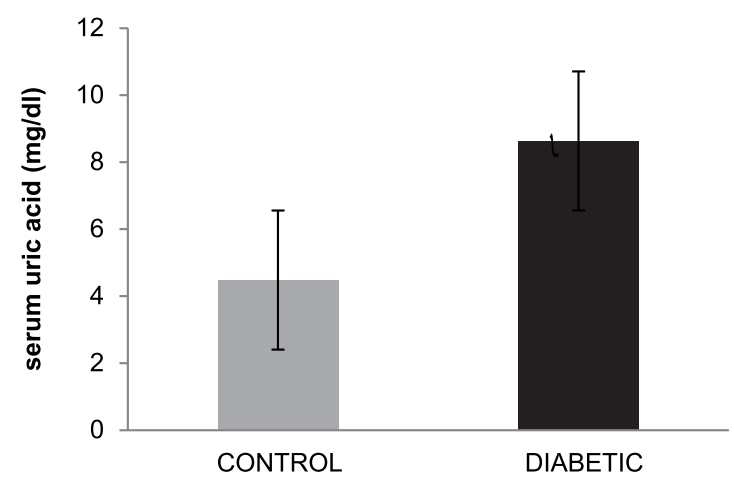

Figure-1. *significantly high as compare to control $p<0.01$

\section{Comparison of Serum Uric Acid among Diabetic, Non Diabetic Males and Females.}

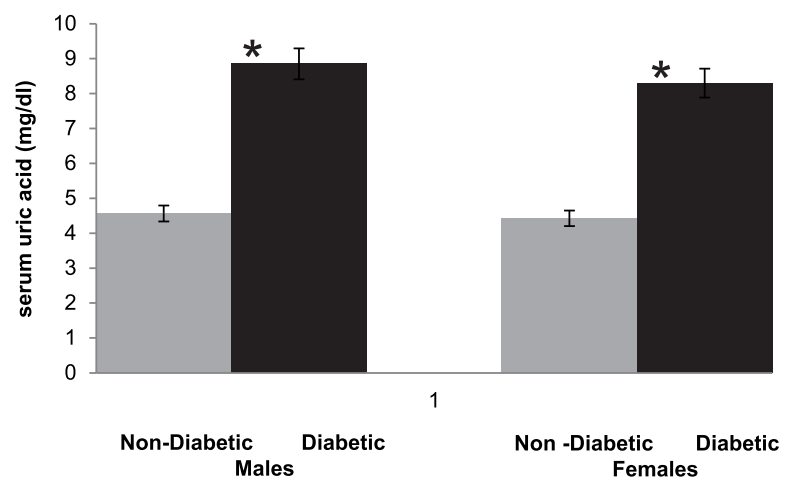

Figure-2. *significantly high as compared to control male and female $p<0.01$

\section{DISCUSSION}

Every year, 32 million peoples loss their lives by diabetes mellitus. Numerous reports bolster a rise in plasma uric acid concentrations in diabetic patients but few invalidate this perception. Our investigation likewise demonstrates comparative outcomes that degree of uric acid was fundamentally on high side in diabetic subjects when contrasted with normal subjects in the both sex. Regardless of whether hyperuricemia is an outcome of diabetes or the other way around is yet to be demonstrated.

The significant enzymes numerously present in tissues like Adenosine deaminase (Adenosine amino hydrolase EC:3,5,4,4) and 5'- Nucleotidase (5'nucleotide phosphohydrolase EC: $3,1,3,5$ ) are liable for the purine catabolism. Adenosine deaminase is accountable for macro and micro vascular damage in diabetes mellitus. ${ }^{12}$ Correspondingly 5' nucleotidase has been asserted raised in type II diabetes mellitus. ${ }^{13}$ Adenosine emulates insulin activity on glucose and lipid metabolism in fatty tissues like myocardium, though it hinders the insulin impact on total hepatic glucose yield recommending that adenosine causes nearby insulin resistance in liver tissue. Adenosine balances activity of insulin on different sites contrastingly and its tissue levels is influenced by ADA levels. ${ }^{14}$ Enzymatic activity of adenosine deaminase and 5'- Nucleotidase rise side by side in blood, which might be because of rise in their levels in the tissues, alongside an ascent in plasma uric acid levels propose that the ascent in uric acid levels seen in our study in type 2 diabetic subjects might be because of enhanced catabolism of purine nucleosides and nucleotides. Kurtul et al., ${ }^{15}$ demonstrated high level of serum ADA activity in patients of type 2 diabetes mellitus with its relationship to $\mathrm{HbA} 1 \mathrm{c}$ and that $A D A$ is important enzyme for ameliorating the action of insulin.

Enzymatic action of various enzymes involved in glycolysis and Kreb's cycle might be decreased by insufficient insulin levels or insulin resistance in type 2 diabetes mellitus, because insulin is responsible for promoting the activities of pyruvate dehydrogenase, hexokinase, phosphofructokinase, pyruvate kinase, a-ketoglutarate dehydrogenase etc. ${ }^{16}$ This low action of these enzymes responsible for increased quantity of glucose-6- phosphate, which could be deviated towards HMP pathway promoting increase in ribose-5-phosphate which is substrate for purine formation. Thus increase in purine synthesis accountable for elevated formation of uric acid. A rise in plasma uric acid levels seen in the present study in type 2 diabetic subjects do support this hypothesis. Uric acid levels inflation in diabetic subjects may also due to alteration glucose metabolism which is especially due to inadequate insulin 
as it is indicated in numerous researches that increased plasma uric acid levels do connect with worsening of glucose homeostasis in type 2 diabetic subjects. ${ }^{17}$ Some researchers also found negative association between hyperuricemia and diabetes mellitus type 2 . Ishihara et .al ${ }^{18}$ studied the association between the urinary excretions of uric acid in diabetes type 2 patients. They found out that more uric acid excreted out in patients with type 2 diabetes when compared to a control that is why in diabetic patients the level of serum uric was low.

\section{CONCLUSION}

The current study results indicate that type 2 diabetic subjects have significantly higher level of uric acid which can increase the rate of morbidity and mortality if not managed.

Copyright@ 21 June, 2020.

\section{REFRENCES}

1. Zuberi NA, Ahsan N, Jafri A, lqbal T, Parveen T. Status of HbA1c in iron deficient diabetic and non-diabetic patients. Professional Med J Feb 2013; 20(1): 054-059.

2. Sandu MM, Protasiewicz DC, Firănescu AG, Lăcătuşu EC, Bîcu ML, Moța M. Data regarding the prevalence and incidence of diabetes mellitus and prediabetes. Romanian Journal of Diabetes Nutrition and Metabolic Diseases. 2016 Mar 1; 23(1):95-103.

3. Zafar J, Bhatti F, Akhtar N, Rasheed U, Bashir R, et al. Prevalence and risk factors for diabetes mellitus in a selected urban population of a city in Punjab. J Pak Med Assoc 2011; 61: 1.

4. Alvarez-Lario B, Macarron-Vicente J: Uric acid and evolution. Rheumatol 2010; 49:2010-2015.

5. M. Chonchol, M. G. Shlipak, R. Katz et al., "Relationship of uric acid with progression of kidney disease," American Journal of Kidney Diseases 2007, vol.50, no.2, pp.239-247.

6. Gui $X Y$, Jin $H Z$, Wang $Z J, X u$ TD. Serum uric acid levels and hyperuricemia in patients with psoriasis: A hospital-based cross-sectional study. A Bras Dermatol. 2018; 93(5):761-3.
7. Nejatinamini et al. Journal of Diabetes \& Metabolic Disorders 2015:14:70.

8. C. K. Kramer, D. Von M"uhlen, S. K. Jassal, and E. Barrett-Connor, "Serum uric acid levels improve prediction of incident type 2 diabetes in individuals with impaired fasting glucose. The Rancho Bernardo Study," Diabetes Care2009, vol. 32, no. 7, pp. 12721273.

9. Oda E, Kawai R, Sukumaran V, Watanabe K. Uric acid is positively associated with metabolic syndrome but negatively associated with diabetes in Japanese men. Internal medicine. 2009;48(20):1785-91.

10. Kodama S, Saito K, Yachi Y, Asumi M, Sugawara A, Totsuka K, Saito A, Sone H. Association between serum uric acid and development of type 2 diabetes. Diabetes care. 2009 Sep 1;32(9):1737-42.

11. Bandaru P, Shankar A. Association between serum uric acid levels and diabetes mellitus. International journal of endocrinology. 2011 Jan 1;2011.

12. Brownlee M. Biochemistry and molecular cell biology of diabetic complications. Nature. $2001 \mathrm{Dec}$ 13;414(6865):813-20. doi: 10.1038/414813a. PMID: 11742414.

13. ONG RL. Adenine Nucleotide Metabolism in Hearts of Diabetic Rats. Diabetes. 1988 May;37:629-36.

14. Gohe MG, Sirajwala HB, Kalaria TR, Kamariya CP. A study of serum adenosine deaminase level in patients with type 2 diabetes mellitus and its correlation with glycemic control. International journal of medical and applied sciences. 2013;2(3):259-67.

15. Sullivan JL, Osborne WR, Wedgwood RJ. Adenosine deaminase activity in lymphocytes. British journal of haematology. 1977 Sep;37(1):157-8.

16. O'Brien RM, Granner DK. Regulation of gene expression by insulin. Biochemical Journal. 1991 Sep 15;278(3):609-19.

17. Rao S, Sahayo BJ. A study of serum uric acid in diabetes mellitus and prediabetes in a south Indian tertiary care hospital. Journal of Health and Allied Sciences NU. 2012 Jun;2(02):18-23.

18. Ishihara M., Shinoda T, Yamada T. Co-occurance of Hypercalciuria and hypouricemia in type. Type 2 Diabetic patients. Diabet Med 1989; 5:406-11. 


\section{AUTHORSHIP AND CONTRIBUTION DECLARATION}

\begin{tabular}{|c|c|c|c|}
\hline Sr. \# & Author(s) Full Name & Contribution to the paper & Author(s) Signature \\
\hline 1 & Naveed Ahsan & Main idea and concept of article. & $\left.9^{4}\right)$ \\
\hline 2 & Fasiha Fatima & Article drafting. & favier \\
\hline 3 & Sarwat Jahan & Sample collection. & \\
\hline 4 & Shahid Zafar & Sample collection \& analysis of & \\
\hline 5 & Jai Kershan & Statistical analysis. & \\
\hline
\end{tabular}

